\title{
A proposito de um dente heterotopico
}

Caso da clinica cirurgica do prof. Benedicto Montenegro, relatado á Sociedade Arnaldo Vieira de Carvalho pelo doutorando Eurico Branco Ribeiro.

\begin{abstract}
NO dia 20 de maio de 1927, tivemos occasião de auxiliar o professor Benedicto Montenegro na intervenção cirurgica reclamada por um caso que julgamos merecedor da attenção dos distinctos consocios.
\end{abstract}

Trata-se do caso de J. M. V., de 32 annos, casado, brasileiro, alfaiate, residente em São José dos Campos, estado de São Paulo. Conta o paciente que, seis annos atrás, por cima de um "bridge" que lhe haviam collocado no logar do canino direito, na arcada dentaria superior, começou a sahir um poucochinho de puz, facto que o impressionou, embora nehuma dor sentisse. Formára-se, evidentemente, uma fistula com fóco suppurativo de provavel localização ossea, já que a manifestação morbida se foi prolongando a despeito de varios tratamentos intentados e levados a effeito. Por isso, em junho de 1926, procurou o nosso doente por um medico, o qual, diagnosticando carie ossea, lhe fez, no dia 9 desse mês e anno, uma curetagem da parte affectada. O periodo post-operatorio decorreu bem, fechando-se a ferida. Mas apenas tres meses se passaram e já uma nova fistula se abriu, com os mesmos caracteristicos da primeira, agora um pouco mais para fóra, acima dos premolares superiores direitos. Era signal de que o fóco profundo ou o terreno predisposto ainda existia. Nova raspagem no osso affectado foi feita, esta a 12 de março de 1927, ao mesmo tempo que o cirurgião extrahiu varios dentes tanto da arcada superior como da inferior, em virtude de pyorrhéa. Desta vez a fistula persistiu, apezar dos curativos cuidadosamente feitos. O doente sentia então defluir pelo orificio "um sangue salgado" que durou alguns dias, sendo substituido por uma gotinha de puz esbranquiçado, que aflorava á pressão nas vizinhanças.

Em vista disso, resolveu-se fazer o exame radiologico da parte affectada. Pelo nosso caro consocio radiologista José Campos foram tiradas quatro chapas, que permittiram estabelecer-se o diagnostico de dente ectopiado.

Esclarecida a causa da persistencia da fistula, era indicado removel-a. Fez-se, portanto, a operação, que consistiu em uma incisão de tres centimetros ao nivel do sulco labio-gengival superior, expo- 
sição da face externa do osso maxillar pela incisão e descollamento do periosteo, trepanação da parede anterior do antro de Highmore, que. assim aberto, permittiu a retirada do dente nella implantado e cujos caracteristicos são todos os do canino direito superior em seu completo desenvolvimento.

A historia pregressa do paciente apresenta varias informações interessantes, que passamos a registar.

Conta elle que sempre teve os dentes fracos. Dizem-lhe que a dentição de leite foi boa, mas que os dentes permanentes vieram aos sete annos, aflorando aos muitos de cada vez. Desde creança teve de frequentar o dentista, pois seus dentes cariavam com facilidade, mas "não faziam differença" para mastigar. Teve muita dor de dente, mas quasi sempre á esquerda; á direita nunca sentiu nevralgia nem teve inchação. $\mathrm{O}$ siso direito superior foi extrahido a tempos. Da arcada superior, mas do lado esquerdo, extrahiram-lhe, a 18 annos, um dente em cuja raiz havia um kysto do tamanho de um grão de arroz.

Pedimos-lhe que nos trouxesse um relatorio dos trabalhos executados pelo seu dentista e esse relatorio está assim redigido:

"Extracções feitas para o sr. J. M. V.:

1. ${ }^{\mathrm{a}}$ extraç̧ão: incisivo lateral superior direito, no dia 8 de setembro de 1918.

2. ${ }^{a}$ extracção: incisivo central superior do mesmo lado, no dia 15 de setembro do mesmo anno.

3. ${ }^{a}$ extracção: bastante trabalhosa, do $1 .^{\circ}$ molar superior esquerdo, que apresentava raizes anomalas, no dia 10 de março de 1920.

4. ${ }^{a}$ extracção: siso inferior esquerdo, no dia 26 de setembro de 1920.

O cliente apresentava ausencia do canino superior esquerdo.

São Paulo, 2 de junho de 1927. (a) Raymundo Reis.

A leitura desse relatorio suggere-nos uma questão que seria interessante deslindar: o dente ausente era, de facto, o canino superior esquerdo ou o dentista teria se enganado no annotar essa anomalia? Embora nada pudessemos apurar a respeito, estamos inclinados a opinar pela segunda hypothese, que não põe entrave á interpretação do caso.

O exame da cavidade buccal do nosso paciente revelou-nos a existencia de uma abobada palatina em ogival, formando as metades direita e esquerda, situadas quasi no mesmo plano da gengiva interna, um sulco mediano anteroposterior bastante desenvolvido. Essa conformação seria o sufficiente, na opinião de varios autores, para explicar semelhante ectopia. Mas como justificar essa conformação anomala? A anamnese do paciente resultou negativa quanto a signaes clinicos de syphilis, a principiar pela inexistencia de accidentes pri- 


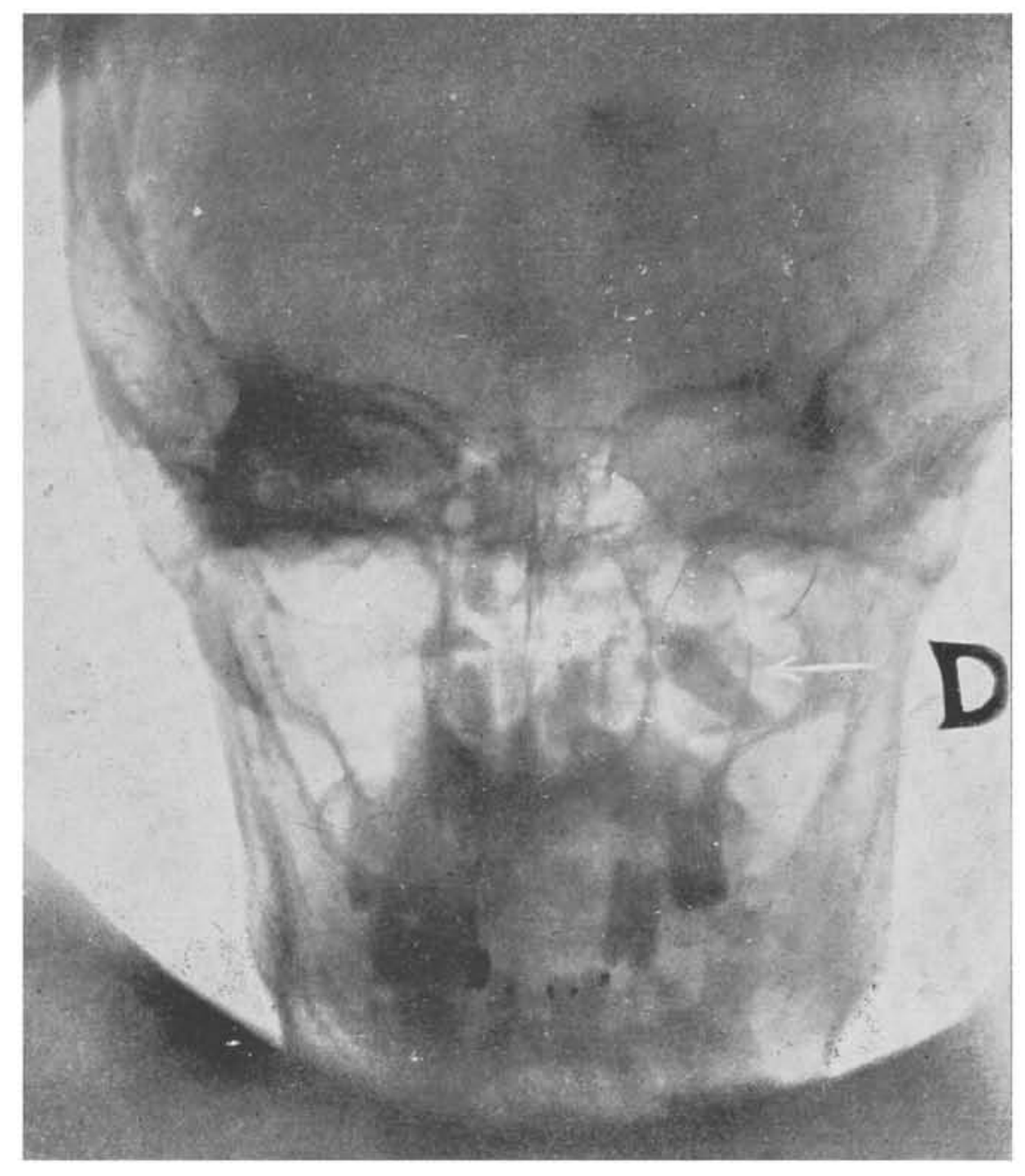

RADIOGRAPHIA DO DOENTE APANHADA DE FRENTE; O DENTE ESTÁ INDICADO POR UMA FLEXA E.II BRANCO. 

marios; mas o exame de sangue, a que o mandamos submetter-se, apresentou a reacção de Wassermann levemente positiva, resultado tambem verificado com o exame do sangue de sua esposa, feito na mesma occasião no Instituto de Hygiene. A herança luetica estava, pois, presente e a ella se atira, frequentemente, em falta de melhor, a responsabilidade de malformações como essa da abobada palatina.

Entretanto, para justifical-a, outro elemento, como a syphilis recurso para as ignorancias da sciencia, é-nos dado presenciar no caso em questão: contou-nos o paciente que seus paes eram primos irmãos e que na familia havia casos de estigmas hereditarios indesejaveis em filhos de conjuges parentes.

Nos casos de anomalias dentarias, lembram ainda alguns autores a coexistencia de vegetações adenoides, procurando estabelecer certa relação entre uma coisa e a outra, que apontam como decorrentes da atresia da arcada dentaria superior. O nosso doente, porém, parece não ter sido portador de vegetações adenoides, quer porque negue qualquer operação na garganta, quer porque conte que sempre respirou pelo nariz, sem sentir a menor difficuldade.

Para explicar a sua ectopia dentaria poderiamos recorrer ainda a um dado da sua historia: conta que, quando creança, foi muito peralta, levando com frequencia violentas quedas. Um abalo forte da face - o choque do maxillar superior contra um plano resistente, por exemplo - podia ter desviado o cordão epithelial em migração, orientando para sitio anomalo o orgam adamantino, que, como se sabe, "domina e determina" o logar de desenvolvimento do dente.

Resta-nos considerar a pathogenia da infecção que molestava o nosso doente. A questão se resume no terreno e suas vias de accesso. A queda do canino de leite superior direito deixou exposto o alveolo correspondente. Alli estava uma porta de entrada, que permaneceu cerrada por muito tempo. A collocação do "bridge" veio abril-a: era um corpo estranho a delimitar um antro onde a multiplicação de germes inocuos ou pathogenos decorreria do menor descuido na hygiene da bocca. Uma vez feita a penetração, os microbios teriam se alojado no canal de nutrição e innervação do dente temporario, que nem sempre regride e desapparece, como bem provou Serres com os seus estudos sobre o canal da dentição de leite do maxillar inferior. Estabelecida o fóco, está explicada a fistulização, onde quer que surja.

O presente caso nos suggere algumas considerações, que talvez não sejam de todo inuteis. Por isso, haveis de permittir que nos aventuremos a trazel-as á vossa apreciação.

Não são poucas as vezes em que o medico é procurado por causa de fistulas gengivaes que resistiram a todo tratamento clinico feito por dentistas. Nesses casos, ao lado da carie ossea e das manifestações pathologicas que se processam nos dentes normalmente implantados, convem pensar sempre nas heterotopias dentarias. Se a extracção do dente ou dos dentes das immediações já foi feita, ou se elles não 
existiam, e, ainda mais, se uma curetagem do fóco apparente foi mal succedida - tanto maior será o motivo de se pensar em ectopia dentaria. Mas não só nos casos de fistula, como em outros de manifestações anomalas da face, a hypothese da existencia de um dente desenvolvido fóra do seu alveolo deve ser aventada. As causas dentarias são commumente apontadas como responsaveis por essas perturbações morbidas, mas poucas são as vezes em que se pensa na heterotopia. Entretanto, é ella muito mais frequente do que geralmente se julga. Já em 1877, a primeira estatistica feita sobre anomalias dentarias, graças aos esforços de Magitot, que colligiu dados com peças de collecções particulares e dos principaes museus e faculdades da Europa e com as informações da literatura - já em 1877 a primeira estatistica feita accusava um total de 193 heterotopias em 2.000 anomalias dentarias (de forma, 92; de volume, 120; de numero, 440; de direcção, 381; de desenvolvimento, 154; de nutrição, 208; de estructura, 168; e de disposição, 244), ou seja uma porcentagem de quasi $10(9,65 \%)$. Em cada dez casos de anomalia dentaria havia, pois, um de ectopia. Hoje, com o radiodiagnostico, essa porcentagem deve ter augmentado bastante. Assim, justifica-se plenamente a recommendação de não se deixar em esquecimento a heterotopia. Reforça-a o facto observado, e citado pelos autores, de que as ectopias dentarias se acompanham geralmente de phenomenos secundarios.

Um dado de valor para o diagnostico de heterotopia é a falta primitiva de um ou mais dentes, principalmente se essa falta se verifica nas proximidades da região affectada. Mas é preciso ter em mente, tambem, que pode occorrer um caso de dente extranumerario, embora tal eventualidade seja rara, ou, ainda, a persistencia de um dente de leite, impedindo o afloramento do dente definitivo, o que mais a miudo se verifica.

Pensando-se em heterotopias dentarias, convem lembrar umas certas regras de frequencia, que sem duvida prestarão auxilio na confirmação do diagnostico. Assim, é bom ter em mente que as ectopias dentarias são mais communs para a arcada superior do que para a inferior, não ultrapassando a face os limites da migração do folliculo em que termina o cordão epithelial. Quando, porém, a heterotopia apparece em outro logar do corpo (craneo, ovarios, testiculos, etc.), então não se trata de anomalia decorrente de migração follicular, mas sim de heterotopia por genese directa (intorsão blastodermica dando heteroplastia classificada como teratoma, segundo alguns autores). Deve-se ter em vista, tambem, que a dentição permanente é quasi que exclusivamente a affectada. E' bom lembrar, ainda, que os dentes mais predispostos ás heterotopias são os caninos, mais os superiores que os inferiores, uns e outros devido ao seu desenvolvimento posterior ao dos dentes com que se relacionam. Vêm a seguir os sisos inferiores, que, ultimos a apparecer e por falta de espaço, podem se incluir no maxillar, occupando logar, ás vezes, no seu ramo montante. 


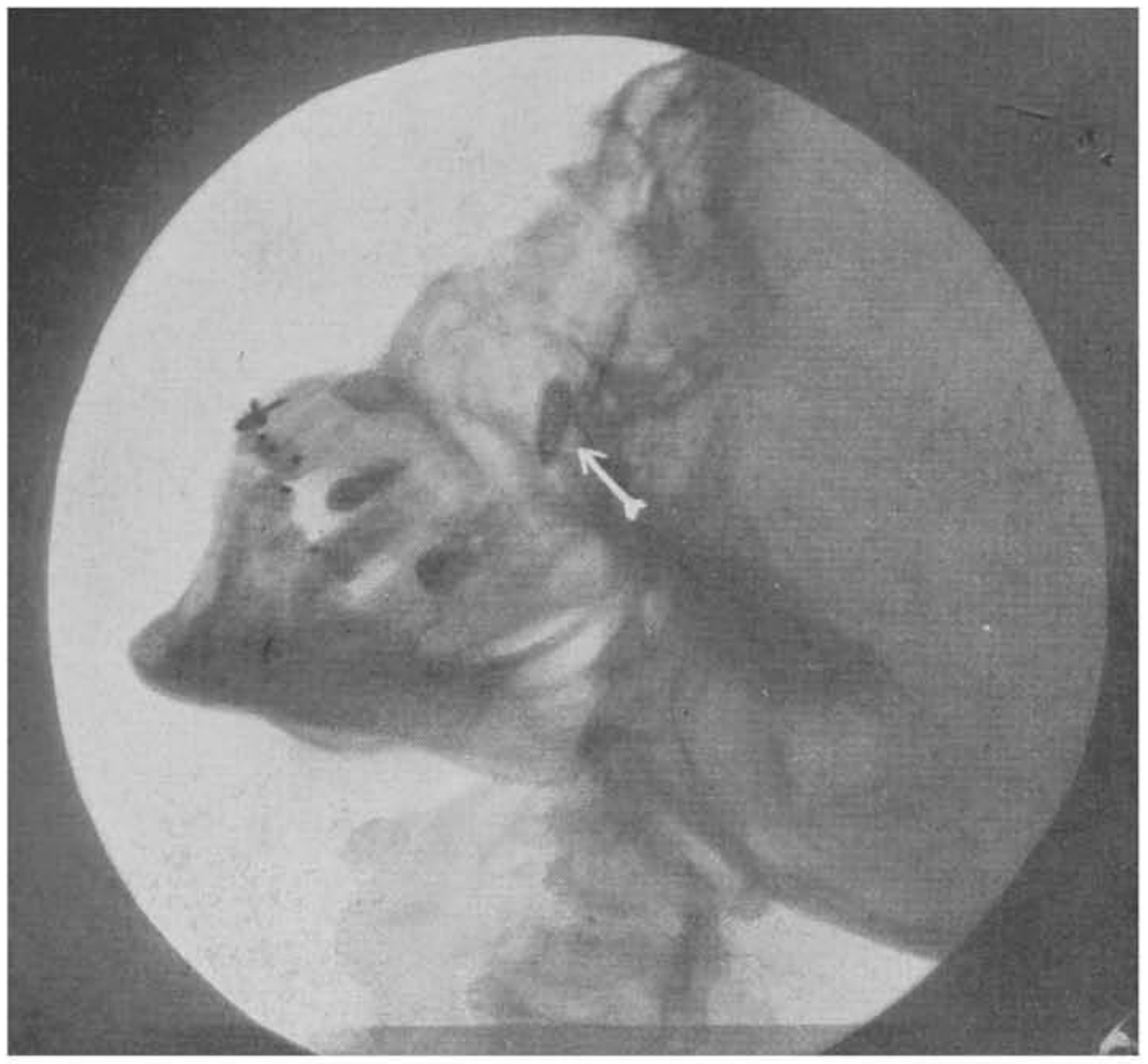

Radiographia do DOENTE APANHADA DE PERFIL; O DENTE ESTÁ INDICADO POR UMA FLEXA EM BRAYCO.

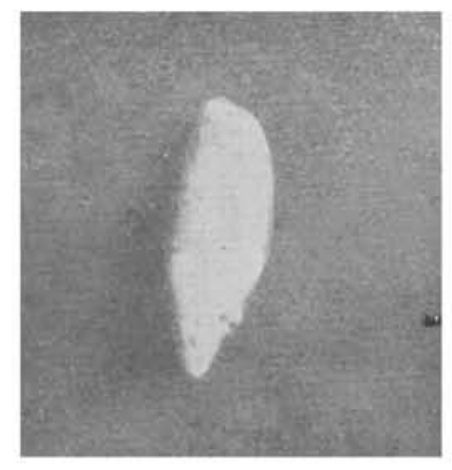

O DENTE EXTRAHIDO, VISTO DE LADO.

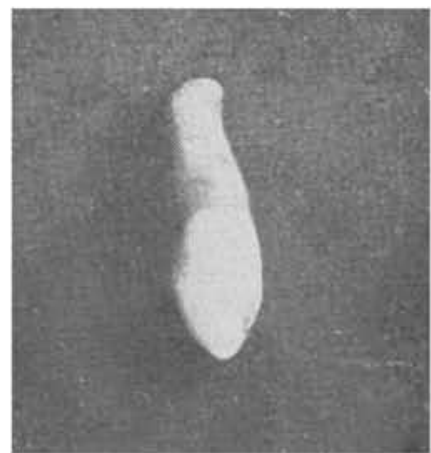

O DENTE EXTRAHIDO, VISTO DE FRENTE. 

Do valor pathogenico das ectopias dentarias só se poderá fazer uma idéa mais segura que a permittida na actualidade quando os dentistas tiverem por praxe pedir systematicamente um exame radiologico logó á primeira suspeita de uma ectopia (falta primaria de dentes nas arcadas, dor nevralgica fazendo pensar em compressão, fistulas que fecham e tornam a abrir ou que nunca se fecham, etc.). Se o dente ectopiado leva annos e annos sem dar signal de si por um symptoma clinico qualquer, tambem pode produzir perturbação que moleste o seu portador. O exame radiologico systematico viria, pois, dar o coefficiente de predisposição morbida das ectopias dentarias.

Entre os casos de ectopia é curioso citar, por ser singular na literatura, o de um odontoma incluido no angulo direito do maxillar inferior de um homem de 35 annos, descripto por J. Salter num dos numeros de 1858 da "Guy's Hospital Reporter" de Londres.

Talvez tambem seja singular o caso observado na clinica de Salles Gomes Junior, de São Paulo, de uma ectopia dentaria a longa distancia por causa traumatica, decorrente de um tiro, cujo projectil fracturou o maxillar inferior, arastando e incluindo entre os fragmentos um dos dentes, que não foi possivel extrahir no acto operatorio.

$\mathrm{De}$ accordo com essas notas ligeiras, pode-se fazer a seguinte eschematização a respeito das ectopias dentarias, postos de margem os casos teratologicos, naturalmente excluidos:

Segundo a localização $\left\{\begin{aligned} & \text { apparente }\left\{\begin{array}{l}\text { exposto } \\ \text { submucoso, subcutaneo. }\end{array}\right. \\ & \text { occulto }\left\{\begin{array}{l}\text { incluso } \\ \text { semiincluso }\end{array}\right.\end{aligned}\right.$

Segundo as causas $\left\{\begin{array}{l}\text { por migração do cordão epithelial (periodo de desen- } \\ \text { volvimento). } \\ \text { por impossibilidade mechanica de afloramento (periodo } \\ \text { de substituição para os dentes que mudam ; perio- } \\ \text { do de erupção para os grandes molares). } \\ \text { por aç̧ão }\left\{\begin{array}{l}\text { choque violento (quedas, bala, etc.) } \\ \text { traumatica } \\ \text { tentativa de extraçãao }\end{array}\right.\end{array}\right.$

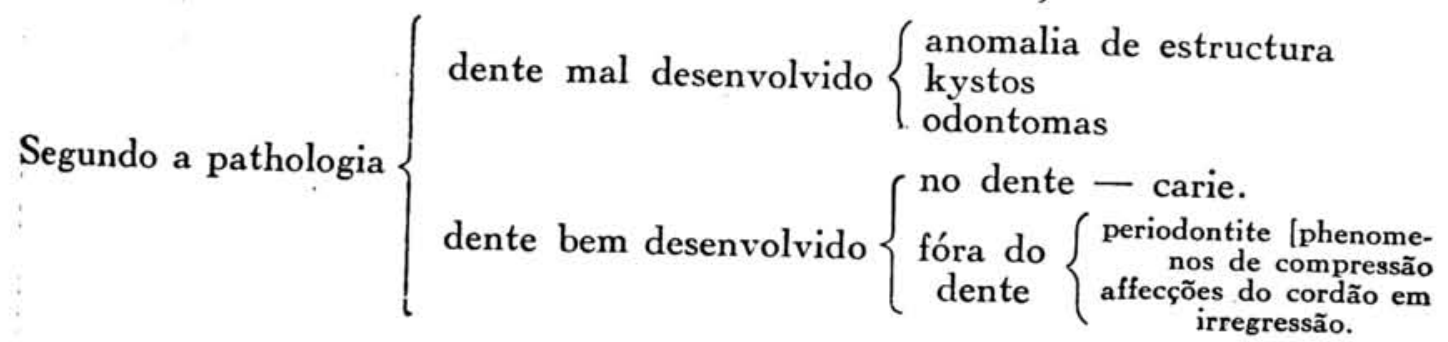

O caso que relatamos seria classificado como um dente occulto semiincluso, ectopico por migração follicular e causando perturbações morbidas extrinsecas localizadas no seu cordão em estado de
irregressão. 


\section{MALEITA}

Novo methodo scientifico de cura da malharia do Prof. Guido Cremonese, com a

\section{“SMALARINA CREMONESE"}

Composto organico de Mercurio e Antimonio, isento de QUiNino Para IMMUNIZAÇÃO E CURA RADICAL DO IMPALUdismo EM TODAS AS SUAS MANIFESTAÇÕES, E O MAIS REBELDES

1 Gaixinha é UMA GURA GOMPLETA

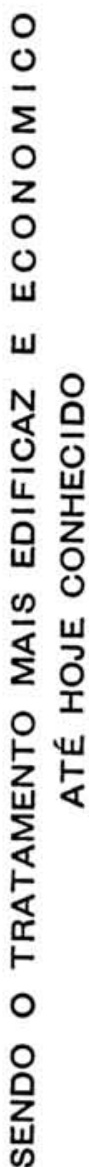

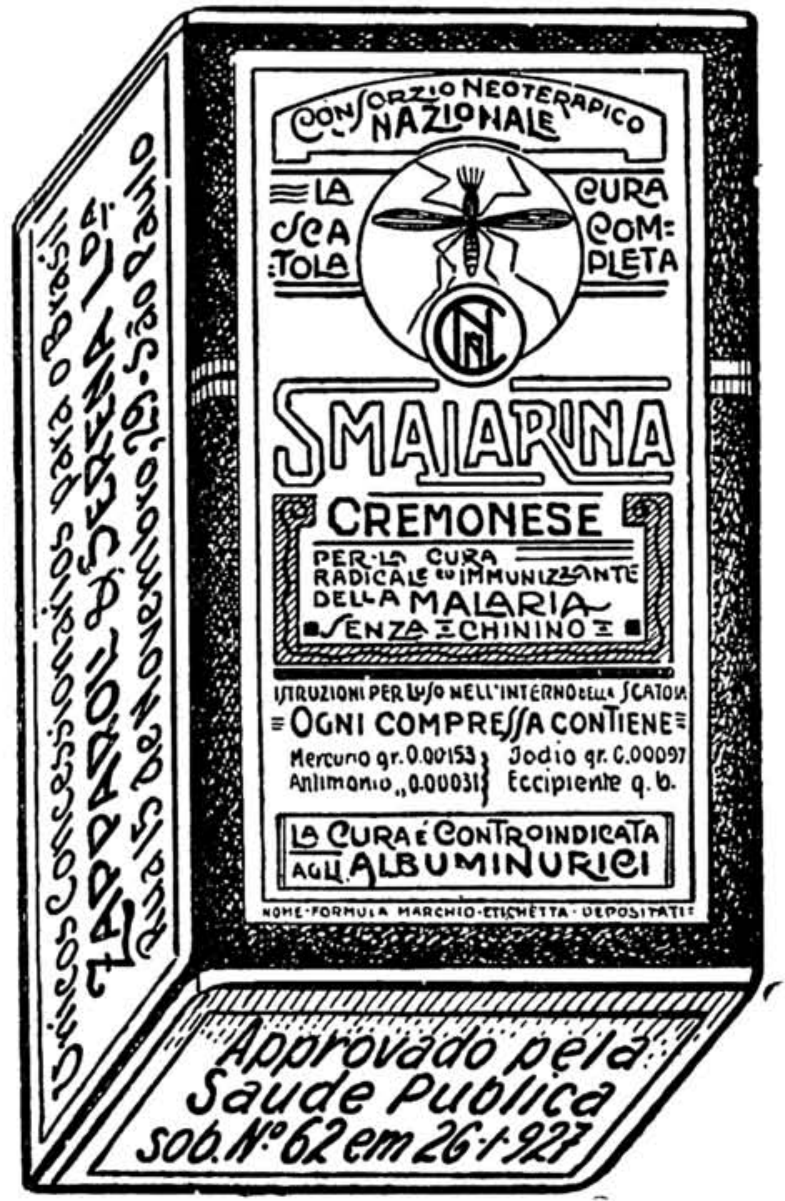

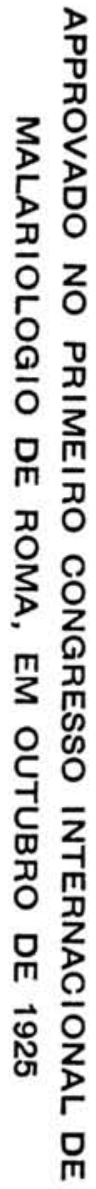

A VENDA EM TODAS AS PHARMACIAS E DROGARIAS DO BRASIL AGENTES GERAES E DEPOSITARIOS

\section{ZAPPAROLI \& SERENA LTDA.}

RUA 15 DẸ NOVEMBRO. 29 - S. PAULO - BRASIL AMOSTRAS GRATUITAS E LITERATURA AOS SNRS. MEDICOS Aprovada pela Saude Publiea sob n.॰ 62, em 26 - 1 - 927 